\title{
Estudo Numérico e Experimental da Evolução Microestrutural e das Propriedades de Juntas Soldadas de Vergalhões pelo Processo GMAW
}

Rudineli Demarque ${ }^{1}$, José Adilson de Castro ${ }^{1}$, Carlos Roberto Xavier ${ }^{2,3}$, Darlene Souza da Silva Almeida ${ }^{1}$, Célio de Jesus Marcelo ${ }^{1}$, Ellem Patrícia dos Santos ${ }^{1}$, Anderson Vergílio de Queiroz ${ }^{1}$

1 Programa de Pós-graduação em Engenharia Metalúrgica - PPGEM, Universidade Federal Fluminense - UFF, Volta Redonda, RJ, Brasil.

2 Centro Universitário de Volta Redonda - UNIFOA, Volta Redonda, RJ, Brasil.

3 Petrobrás, Volta Redonda, RJ, Brasil.

Recebido: 18 Out., 2015

Aceito: 14 Dez., 2015

E-mails: rudineli.demarque@hotmail. com (RD), joseadilsoncastro@id.uff.br (JAC), xavier@metal.eeimvr.uff.br (CRX), darlene.s.s@hotmail.com (DSSA),celiomarcelo@ig.com.br (CJM), ellemph@ gmail.com (EPS), andersonvirgilio@ yahoo.com.br (AVQ)
Este é um artigo publicado em acesso aberto (Open Access) sob a licença Creative Commons Attribution Non-Commercial, que permite uso, distribuição e reprodução em qualquer meio, sem restriçōes desde que sem fins comerciais e que trabalho original seja corretamente citado.
Resumo: Este trabalho constitui um estudo dos vergalhões CA-50 da classe dos aços SAE 1026. Para um melhor controle das propriedades mecânicas da junta soldada foi realizado este estudo, o conhecimento de certas variáveis é de grande importância para encontrar os parâmetros ideais de soldagem, e os respectivos resultados microestruturais e consequentemente sobre as propriedades mecânicas da junta soldada. Para realização deste estudo foi realizado um estudo do material como recebido para a fixação de uma base sólida de comparação. Foi realizada a soldagem do material utilizando como gás de proteção argônio com $20 \%$ de dióxido de carbono, o arame utilizado foi o cobreado ER70S-6, as juntas soldadas foram do tipo transpasse com monitoramento de temperatura através de termopares para dois aportes térmicos distintos. Um código numérico computacional foi desenvolvido para simular os fenômenos que ocorrem no processo (gradiente de temperatura, transformações de fases, transferência de calor). As juntas soldadas não apresentaram martensita como fase frágil, o metal de solda apresentou estrutura dendrítica, a ZTA apresentou duas regiões distintas com tamanhos de grão diferentes tudo isso devido ao gradiente de temperatura, que também originou características distintas do cordão de solda, ZTA, fases formadas e tamanhos de grão distintos.

Palavras-chave: Soldabilidade; GMAW; Simulação computacional; Concreto armado.

\section{Numerical and Experimental Study of Microstructure Evolution and Properties of Welded Joints of Rebars by GMAW Process}

\begin{abstract}
This work is a study of rebar CA-50 class of steels SAE 1026. To better control the mechanical properties of the weld was carried out this study, knowledge of certain variables is very important to find the optimal parameters of welding, and the results microstructure and therefore on the mechanical properties of the welded joint. For this study was conducted a study of the material as received for establishing a solid basis for comparison. Welding the material using argon as protective gas of $20 \%$ carbon dioxide was performed, the wire used was ER70S-6 coppered, welded joints were of the type with crossover temperature monitoring thermocouple through two distinct thermal contributions. A computational numerical code was developed to simulate the phenomena occurring in the process (temperature gradient, phase transformations, heat transfer). Welded joints did not show how fragile martensite phase, the weld metal showed dendritic structure, the ZTA presented two distinct regions with different grain sizes all this due to the temperature gradient, which also originated distinct characteristics of the weld bead, ZTA, stages formed and different grain sizes.
\end{abstract}

Key-words: Weldability; GMAW; Computer simulation; Reinforced concrete.

\section{Introdução}

Os vergalhões de maneira geral são utilizados juntamente ao concreto, pois o mesmo é um material que apresenta elevada resistência à compressão, porém possui baixa resistência à tração, cerca de $10 \%$ de sua resistência à compressão. Logo é essencial a utilização de vergalhões associados ao concreto, pois assim a baixa resistência à tração do concreto é compensada pela elevada resistência à tração do vergalhão. Assim surgiu o conceito de concreto armado (CA), ou seja, a utilização dos aços longos na forma de armaduras metálicas a fim de absorverem as tensões de tração, enquanto o concreto absorve as tensões de compressão que são impostas na estrutura [1]. 
Estudo Numérico e Experimental da Evolução Microestrutural e das Propriedades de Juntas Soldadas de Vergalhões pelo Processo GMAW

O constante crescimento da indústria de construção civil impulsionou também a demanda por produtos cada vez melhores, aumentando também o custo dos mesmos. Isso aumentou a demanda por aços longos com propriedades diferenciadas, gerando assim a necessidade de um desenvolvimento cientifico e tecnológico nas indústrias de aços longos, buscando uma melhoria da qualidade sem alterar significativamente o custo do produto. Esse desenvolvimento possibilitou aplicações mais arrojadas, com layouts diferenciados e revolucionários na realização de projetos e execução de obras na engenharia [2].

Os vergalhões são fabricados nas indústrias mini-mill, produzidos em grande maioria através do processo de laminação a quente, onde suas propriedades mecânicas são obtidas parte pela composição química inicial da liga metálica, e parte pelo processamento termomecânico que a liga foi submetida. Quando se utiliza a composição química para garantir as propriedades mecânicas do produto final, neste caso o vergalhão, adições maiores de carbono e manganês são utilizadas para obter essa maior resistência mecânica. Porém a elevação destes elementos ocasiona um decréscimo indesejado na soldabilidade do mesmo. Para contornar essa redução da soldabilidade dos vergalhões foram criadas várias normas para realizar o controle do carbono equivalente, conferindo ao aço assim uma melhor soldabilidade [3].

Os elementos de liga adicionados ao aço estrutural devem ser severamente controlados com a finalidade de possibilitar o monitoramento da microestrutura resultante do processo de soldagem, com o objetivo de evitar a formação de fases frágeis no resfriamento da junta soldada. A adição dos elementos de liga aumenta a temperabilidade do aço favorecendo a transformação martensítica no resfriamento, fato indesejado numa junta soldada, pois a martensita é uma fase fragilizante [4].

Quando se deseja fabricar armaduras de vergalhões para a utilização em estruturas de concreto armado, é essencial a aplicação de um processo de soldagem para realizar a união destes. Esta união metálica deve apresentar propriedades mecânicas iguais ou superiores as do metal base, para assim garantir a qualidade da armadura metálica a ser utilizada. O processo de soldagem utilizado para a realização da união dessa estrutura pode variar, neste estudo esta união será realizada através da soldagem GMAW (Gas Metal Arc Welding) em uma junta com emenda por transpasse [5].

Buscando contribuição para ampliar o conhecimento das transformações metalúrgicas que ocorrem na junta soldada, estas influenciam de forma direta nas propriedades mecânicas da junta soldada. Este trabalho objetiva a realização de um estudo experimental e numérico da soldabilidade do vergalhão CA50 (aço SAE 1026), avaliando fatores como a influência da variação do aporte térmico sobre as características microestruturais da ZTA e da ZF assim como o dimensionamento do cordão de solda e ZTA, e das propriedades mecânicas da junta soldada.

Amostras do vergalhão foram soldadas por meio do processo GMAW (Gas Metal Arc Welding) com corrente pulsada e diferentes aportes térmicos variando apenas a velocidade de soldagem. $O$ gás de proteção utilizado foi o Argônio com $20 \%$ de CO2, durante a soldagem experimental a evolução da temperatura foi monitorada através de termopares fixados em alguns pontos dos CP's, posteriormente utilizada para auxiliar o entendimento da microestrutura obtida na junta soldada e para ajustar os parâmetros do modelo numérico utilizado.

Após a soldagem as juntas passaram por análise macroscópica, posteriormente a ZTA e a ZF foram caracterizadas por meio de microscopia óptica (MO), a fim de avaliar as alterações microestruturais provenientes do ciclo térmico que a junta sofreu durante o processo de soldagem. Um modelo numérico foi implementado com base nas equações de transporte de calor, as quais foram solucionadas numericamente pela técnica de volumes finitos. As equações foram implementadas utilizando-se linguagem de programação FORTRAN simular o histórico térmico de soldagem do vergalhão CA50.

\section{Metodologia}

A metodologia empregada neste trabalho compreende avaliações experimentais visando obter parâmetros para o modelo computacional, a simulação computacional do processo e comparação dos resultados experimentais e calculados. Visando a utilização dos resultados calculados para previsões de condições locais de temperaturas, taxas de resfriamento e microestruturas locais resultantes para diferentes condições de soldagem, foram escolhidas duas condições limites de aportes térmicos $(1,3 \mathrm{~kJ} / \mathrm{mm}$ e 1,8 kJ/mm) que podem resultar em significantes diferenças nas propriedades da junta soldada. 


\subsection{Materiais}

O material utilizado na parte experimental foi recebido na forma de barras: doze vergalhões CA50 de aço SAE1026, nervurados com $16 \mathrm{~mm}$ de diâmetro e um metro de comprimento, esses são da mesma corrida logo possuem a mesma composição química. Esse vergalhão foi soldado pelo processo GMAW, com uma junta por transpasse que segundo a norma ABNT NBR 6118 [6] deve possuir ao menos dois cordões de solda longitudinais, cada um deles com comprimento não inferior a cinco vezes o diâmetro da barra, e afastados no mínimo cinco vezes o diâmetro da barra conforme ilustra a Figura 1.

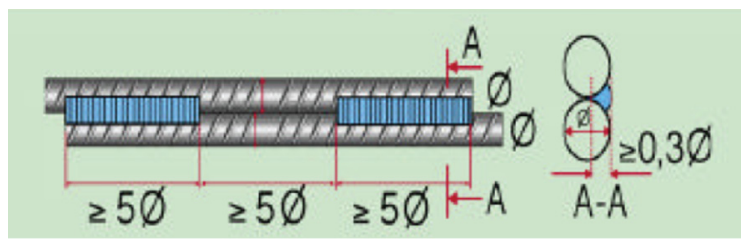

Figura 1. Emenda por transpasse prevista na norma ABNT NBR 6118 [6].

Foi retirada uma amostra do vergalhão como recebido tanto para caracterização microestrutural como para análise da composição química do material. No laboratório de soldagem da EEIMVR-UFF foram cortadas quarenta corpos de prova de $100 \mathrm{~mm}$ para realização de testes com a finalidade de encontrar os parâmetros de soldagem adequados. Também foram cortadas quatro corpos de prova de $220 \mathrm{~mm}$ para confecção de 2 CP's com diferentes aportes térmicos para análise metalográfica, aquisição de dados e utilização no modelo numérico. A Tabela 1 apresenta a composição química do aço.

As soldas foram realizadas no presente trabalho por meio do processo GMAW pulsado, os seguintes consumíveis foram utilizados no processo: uma mistura gasosa para proteção do arco e da poça de fusão, e um arame de adição. A Tabela 1 apresenta as composições químicas do vergalhão, da mistura gasosa e do arame de adição respectivamente. Após o procedimento de soldagem do vergalhão é desejada uma estrutura isenta de fases fragilizadoras, com propriedades mecânicas iguais ou superiores as do material como recebido com o objetivo de evitar o surgimento de uma região fragilizadoras na junta soldada, que atuaria com um concentrador de tensões possivelmente ocasionando o rompimento na região da solda.

Tabela 1. Composição química do vergalhão CA-50 do Gás e do Arame. Expressões para os valores de Cp e K acima e abaixo de $800^{\circ} \mathrm{C}[7]$.

\begin{tabular}{|c|c|c|c|c|c|c|c|c|c|c|c|c|c|c|c|}
\hline & $\% \mathrm{C}$ & $\% M n$ & $\% S i$ & \%P & $\% S$ & $\% \mathrm{Cu}$ & $\%$ Sn & $\% \mathrm{Ni}$ & $\% \mathrm{Cr}$ & \%Mo & $\% \mathrm{Nb}$ & $N(p p m)$ & $\% A r$ & \%02 & $\% \mathrm{CO} 2$ \\
\hline Vergalhão & 0,23 & 0,6 & 0,15 & - & - & - & - & - & - & - & - & - & - & - & - \\
\hline CA-50 & 0,28 & 0,9 & 0,3 & 0,05 & 0,05 & 0,45 & 0,1 & 0,3 & 0,25 & 0,1 & - & 150 & - & - & - \\
\hline Gás & - & - & - & - & - & - & - & - & - & - & - & - & 80 & - & 20 \\
\hline $\begin{array}{c}\text { Arame } \\
(1,2 \mathrm{~mm})\end{array}$ & 0,06 & 1,4 & 0,8 & 0,025 & 0,035 & 0,5 & - & - & - & - & - & - & - & - & - \\
\hline ER70s-6 & 0,15 & 1,85 & 1,15 & Max. & Max. & Max. & - & - & - & - & - & - & - & - & - \\
\hline $\begin{array}{l}\text { Expressões } \\
\text { para Cp }\end{array}$ & \multicolumn{12}{|c|}{$\begin{array}{c}\mathrm{Cp}(\mathrm{J} / \mathrm{kg} \mathrm{K})=479,9+0,02749 \mathrm{~T}+0,000698 \mathrm{~T} 2 \\
\mathrm{Cp}(\mathrm{J} / \mathrm{kg} \mathrm{K})=633,571+0,08214 \mathrm{~T}\end{array}$} & \multicolumn{3}{|c|}{$\begin{array}{l}\mathrm{T}<800^{\circ} \mathrm{C} \\
\mathrm{T}>800^{\circ} \mathrm{C}\end{array}$} \\
\hline $\begin{array}{l}\text { Expressões } \\
\text { para K }\end{array}$ & \multicolumn{12}{|c|}{$\begin{array}{c}\mathrm{K}(\mathrm{W} / \mathrm{mK})=52,526-0,01419 \mathrm{~T}-0,000023713 \mathrm{~T} 2 \\
\mathrm{~K}(\mathrm{~W} / \mathrm{mK})=-18+0,06833 \mathrm{~T}-0,000016666 \mathrm{~T} 2\end{array}$} & \multicolumn{3}{|c|}{$\mathrm{T}<800^{\circ} \mathrm{C}$} \\
\hline
\end{tabular}

\subsection{Procedimentos experimentais}

A parte experimental do presente trabalho seguiu as seguintes etapas: caracterização microestrutural do material como recebido (tamanho de grão e quantificação de fases por $\mathrm{MO}$ ), corte de quatro amostras do material com $220 \mathrm{~mm}$ de comprimento cada, soldagem dos vergalhões por transpasse pelo processo GMAW com corrente pulsada utilizando dois aportes diferentes, corte de uma amostra soldada com cada aporte, caracterização das 
Estudo Numérico e Experimental da Evolução Microestrutural e das Propriedades de Juntas Soldadas de Vergalhões pelo Processo GMAW

juntas soldadas (dimensionamento do metal de solda e da ZTA através da análise da macrografia no projetor de perfil, medição do tamanho de grão e quantificação de fases por $\mathrm{MO}$ ), comparação dos resultados experimentais e calculados.

O processo de soldagem empregado foi o GMAW (Gas Metal Arc Welding), utilizando corrente pulsada, este processo foi realizado por meio do equipamento sinérgico modelo MIG PULSE 4001 DP - CASTOLIN EUTECTIC, instalado no laboratório de soldagem da EEIMVR-UFF. O equipamento sofreu uma adaptação com o objetivo de automatizá-lo, com o acoplamento da tocha de soldagem a um carro móvel, este carro móvel tem sua velocidade controlada por um inversor de frequência. Com essa adaptação um controle mais rigoroso da velocidade de soldagem pode ser realizado durante cada procedimento.

Para que a soldagem fosse realiza com êxito e os resultados obtidos com o procedimento fossem satisfatórios, foram realizadas soldas com diferentes parâmetros em CP's denominados CPs't (corpos de prova teste), estes foram compostos por um grupo de 30 procedimentos de soldagem, com o objetivo de se obter os parâmetros ideais para realização do processo. Os CPs't tinham um comprimento de $150 \mathrm{~mm}$, e o procedimento foi realizado sem a aquisição de dados, apenas realizando o controle da corrente, tensão e velocidade de soldagem. Após o procedimento de soldagem e análise de amostras retiradas dos CPs't soldados, foram determinadas a corrente de $220 \mathrm{~A}$, e a tensão de $28,5 \mathrm{~V}$ como valores de parâmetros de soldagem mais adequados para realização do presente trabalho. Com a finalidade de obter a variação do aporte térmico a velocidade de soldagem foi o parâmetro escolhido para variar. A soldagem em todos os vergalhões foi realizada com a deposição do material de adição (arame) em um único passe, sendo este um cordão de $180 \mathrm{~mm}$ de comprimento nos CP's de $220 \mathrm{~mm}$.

Os dois CP's do vergalhão CA50 foram soldados com proteção gasosa de Argônio com $20 \%$ de CO2, arame de adição ER70S-6 com 1,2 mm de diâmetro e os seguintes aportes térmicos: 1,3KJ/mm (limite inferior); 1,8KJ/mm (limite superior). Os parâmetros de soldagem utilizados para os dois CP's foram os mesmos, sendo a variação do aporte obtida apenas pela variação da velocidade de soldagem (determinada pela velocidade do carro programada no equipamento) conforme detalhado na Tabela 2. A fim de que se pudesse ser feitas comparações da microestrutura na ZF e ZTA, e suas dimensões. E assim avaliar o efeito da variação do aporte térmico na junta soldada, obtendo quais tendem a serem os parâmetros mais favoráveis que resultem em uma junta soldada com melhores características macro e microestruturais, logo com melhores propriedades mecânicas.

Tabela 2. Parâmetros de soldagem dos corpos de prova.

\begin{tabular}{ccccc}
\hline Amostra & $\begin{array}{c}\text { Tensão } \\
\text { (V) }\end{array}$ & $\begin{array}{c}\text { Amperagem } \\
(\mathbf{A})\end{array}$ & $\begin{array}{c}\text { Velocidade } \\
(\mathbf{m m} / \mathbf{s})\end{array}$ & $\begin{array}{c}\text { Aporte } \\
(\mathbf{K J} / \mathbf{m m})\end{array}$ \\
S1 & 28,5 & 220 & 3,86 & 1,3 \\
S3 & 28,5 & 220 & 2,79 & 1,8 \\
\hline
\end{tabular}

O equipamento utilizado para realizar o procedimento de soldagem, foi um equipamento sinérgico de modo que apenas alguns parâmetros e informações são fornecidos à máquina e ela ajusta os outros parâmetros automaticamente durante toda a soldagem, como no caso dos parâmetros de pulsos de corrente e tensão. À máquina só são fornecidos parâmetros como tensão média e corrente média, que são funções do tipo do material da dimensão do arame e composição do gás. O stick-out foi ajustado manualmente obedecendo ao limite máximo de 10 vezes o diâmetro do arame. A vazão do gás foi regulada por meio de uma válvula no cilindro, e a velocidade de soldagem é ajustada pela velocidade do carro através da frequência do motor do carro através do inversor de frequência.

Após a aquisição dos dados experimentais e das primeiras análises dos resultados, para confrontar os resultados obtidos e para possibilitar suposições de diferentes situações, foi avaliada a necessidade e os benefícios que a implementação de um modelo numérico que simulasse o processo traria ao presente trabalho. Além de simular o gradiente de temperatura, as transformações de fases e outros fenômenos o modelo poderia simular com confiabilidade uma infinidade de situações e combinações de diferentes possibilidades, que não seriam viáveis no experimento prático. Sendo assim fica clara a importância para o trabalho da implementação de um modelo numérico que torne possível a realização da simulação computacional do processo e fenômenos presentes no mesmo. 


\subsection{Simulação computacional}

Para modelar o processo de soldagem e fazer a previsão de temperatura no vergalhão foram considerados os mesmos parâmetros do processo experimental. Além disso, algumas considerações adicionais foram feitas a fim de tornar viável a simulação computacional: perda de calor na superfície do vergalhão por convecção e radiação, não ocorrência de difusão de elementos químicos entre o metal adicionado e o metal base e composição química do metal de base constante. 0 modelo numérico de previsão de temperatura consiste na resolução da equação de conservação de energia (Equação 1) aplicada sobre o volume do vergalhão como domínio de estudo. Onde $\rho$, $\mathrm{Cp}$ e k são propriedades termofísicas do material, respectivamente, densidade, calor específico, condutividade térmica, u e T são os campos de velocidade e temperatura, respectivamente. S é o termo fonte correspondente a todas as fontes de entrada e/ou perda de calor durante o processo [8].

$$
\frac{\partial}{\partial t}\left(\rho c_{p} T\right)+\operatorname{div}\left[\rho c_{p}(\vec{u}) T\right]=\operatorname{div}[\mathrm{k}[(\operatorname{grad}(\mathrm{T}))]]+S
$$

No processo GMAW a fonte de calor é o arco elétrico que aqui foi descrito pelo modelo duplo-elipsóide, objeto de estudo neste trabalho. Este modelo propõe uma fonte de calor tridimensional onde a distribuição de calor é modelada (em volume) como duas elipses, uma à frente e outra atrás da tocha, conforme Figura 2.

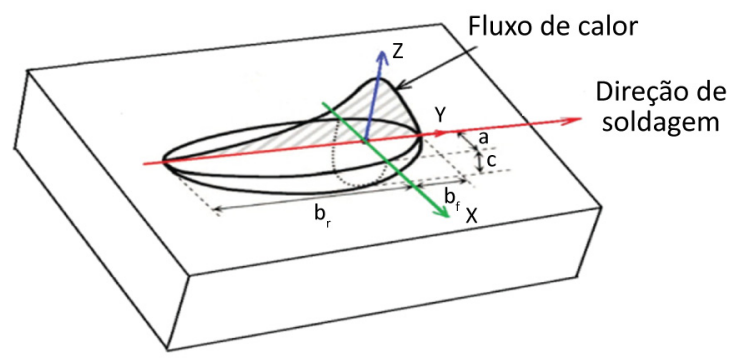

Figura 2. Modelo duplo-elipsóide para fonte de calor utilizado para reproduzir as condições de soldagem no vergalhão CA-50.

O fluxo de calor neste modelo é equacionado de forma separada. A Equação 2 descreve o fluxo de calor à frente da fonte enquanto a Equação 3 descreve a distribuição do fluxo de calor atrás da fonte [9].

$$
\begin{aligned}
& q_{f}(x, y, z)=\frac{6 \sqrt{3} f_{f} Q}{a b_{f} c \pi \sqrt{\pi}} e^{-3\left(\frac{x}{a}\right)^{2}} e^{-3\left(\frac{y}{b_{f}}\right)} e^{-3\left(\frac{z}{c}\right)^{2}} \\
& q_{r}(x, y, z)=\frac{6 \sqrt{3} f_{r} Q}{a b_{r} c \pi \sqrt{\pi}} e^{-3\left(\frac{x}{a}\right)^{2}} e^{-3\left(\frac{y}{b_{r}}\right)} e^{-3\left(\frac{z}{c}\right)^{2}}
\end{aligned}
$$

Onde $Q$ corresponde à energia adicionada por unidade de tempo na soldagem (em Watts) e pode ser calculada pelos parâmetros de soldagem corrente (i) e tensão $(\mathrm{V})$ por meio da equação $Q=\eta V i$; $\eta$ é um fator de rendimento do processo, aqui admitido como 0,8 ; ff e fr correspondem às frações do calor total distribuídos nos volumes dos elipsoides compreendidos à frente da tocha ( $\mathrm{ff}$ ) e atrás ( $\mathrm{fr}$ ), onde $\mathrm{ff}+\mathrm{fr}=2$. A variável qf e qr indicam a quantidade de calor adicionado à frente e atrás da tocha respectivamente. Já as variáveis a, c, bf e br estão relacionadas à geometria da distribuição (Figura 3), enquanto as coordenadas $x$, y e $z$ correspondem aos pontos no interior da peça em relação a um referencial móvel (correspondente à velocidade de soldagem), com origem no centro do arco. Portanto, as coordenadas $x$, y e $z$ são funções do tempo e representam o movimento da tocha ao longo do procedimento de soldagem. Neste trabalho os parâmetros geométricos da fonte $(a, c, b f$ e br) foram inicialmente 
Estudo Numérico e Experimental da Evolução Microestrutural e das Propriedades de Juntas Soldadas de Vergalhões pelo Processo GMAW

ajustados por meio dos dados experimentais coletados pelos termopares. Posteriormente, variações nos valores ajustados foram realizadas a fim de se conhecer a sensibilidade do modelo a estes parâmetros.

Condições de contorno (CC's) e inicial (Cl) são aplicadas à Equação 1. A solução da Equação 1 com as condições de contorno e iniciais e a representação da fonte móvel permite, então, a obtenção dos valores de temperaturas a todos os instantes durante o procedimento de soldagem e seu posterior resfriamento [10]. Quanto às condições de contorno, foram admitidas duas condições térmicas: convecção e radiação pelas superfícies da peça. A fonte de calor tridimensional e transiente (representadas pelas Equações 2 e 3 ) são incluídas no termo fonte da Equação 1 e pode-se, portanto, resolver o problema acoplado considerando as não linearidades devidas a propriedades termofísicas (dependentes da temperatura e composição) e à fonte de calor móvel do modelo duplo-elipsóide descrito pelas Equações 2 e 3. A convecção e radiação nas superfícies da chapa, classicamente descritos por $\mathrm{qc}=\mathrm{h}(\mathrm{T}-\mathrm{TO})$ e $\mathrm{qr}=\varepsilon \sigma\left(\mathrm{T}^{4}-\mathrm{T} 0^{4}\right)$, respectivamente [11]. Onde qc e qr são respectivamente o calor gerado à frente e atrás da tocha, T a temperatura final e T0 a inicial, $\sigma$ é a constante de stefan boltzmann $\left(\sigma=5,67 \times 10^{-8}\left[\mathrm{~W} / \mathrm{m}^{2} . K^{4}\right]\right)$, foram admitidos emissividade $(\varepsilon)$ igual a 0,6 e coeficiente de convecção $(h)$ igual a $15 \mathrm{~W} /\left(\mathrm{m}^{2} . K\right)$. Quanto à condição inicial, admite-se que todas as faces da chapa tenham temperatura igual a $25^{\circ} \mathrm{C}$ no início do processo [12].

Aplicadas as CC's e Cl, uma solução para a Equação 1 é obtida por meio do método de volumes finitos, conforme detalhado por Xavier et al. [13]. Os resultados de distribuição de temperatura obtidos por meio do modelo foram adicionalmente utilizados para previsão de tamanho de grão final da junta soldada utilizando um modelo cinético de crescimento de grão, descrito pela Equação 4 [14].

$$
\frac{d G}{d t}=\frac{k(T)}{G^{n(T)-1}}
$$

Onde a constante cinética $k(T)=7,01019 \times 10^{-16}(T-273)-1,75 \times 10^{-15}$ e o expoente $n(T)=2,44$, ambos ajustados com resultados experimentais para o tamanho de grão. Os parâmetros $k(T)$ e $n(T)$ são característicos do material em estudo e representam a dinâmica de crescimento de grão em condições isotérmicas e não isotérmicas. Neste estudo, foram obtidos através de método iterativo medindo-se simultaneamente o histórico térmico da soldagem de aquecimento, resfriamento e consequente tamanho de grão médio final na zona afetada pelo calor. Os parâmetros $k(T)$ e $n(T)$, portanto, representam o comportamento do aço do vergalhão $C A-50$ que devem ser utilizados para a solução da Equação 4 assumindo-se como tamanho de grão inicial aquele medido no material base (como recebido).

\subsection{Corte e preparação metalográfica}

Já os vergalhões soldados com dois aportes diferentes, foram retiradas amostras do centro de cada $\mathrm{CP}$, região onde o processo estava estabilizado (para análise de fases presentes, medição de dimensões do ZF e ZTA). As amostras foram cortadas na seção transversal do cordão de solda em um tamanho que dispensou o embutimento em baquelite conforme Figura 3.

No total foram retiradas duas amostras, identificadas como S1(solda 1), e S3 (solda 3). As amostras foram lixadas em lixadeira manual com lixas de carbeto de silício com as seguintes granulometrias: 100, 220, 320, 400, 600, 800, 1000 e 1200 mesh. Em seguida foi realizado o polimento mecânico da amostra em politizes manuais utilizando como abrasivo sílica com granulometria de $1 \mu \mathrm{m}, 0,3 \mu \mathrm{m}$ e $0,05 \mu \mathrm{m}$. Então as amostras foram finalmente atacadas por imersão com o reagente Nital 3\%.

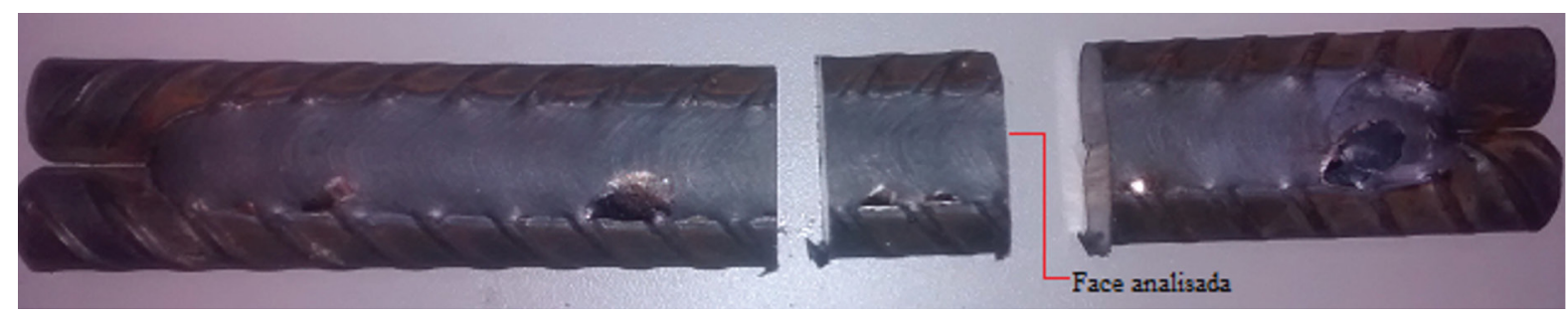

Figura 3. Corte para retirada de amostra do CP soldado. 


\section{Resultados e Discussões}

\subsection{Juntas soldadas}

Neste tópico é realizada uma comparação entre as dimensões dos cordões de solda utilizando dois diferentes aportes térmicos. Como largura, profundidade, área do MS e área da ZTA para os diferentes aportes utilizados. A Tabela 3 apresenta os valores da largura e altura do MS, assim como os valores das áreas da ZTA e do MS, para os cortes transversais nas amostras soldadas com os dois aportes, com a finalidade de estudar as características do cordão de solda.

Tabela 3. Dimensões dos cordões de solda e ZTA para os diferentes aportes.

\begin{tabular}{cccccc}
\hline $\begin{array}{c}\text { Aporte } \\
\mathbf{k j} / \mathbf{m m}\end{array}$ & Amostra & $\begin{array}{c}\text { largura MS } \\
(\mathbf{m m})\end{array}$ & $\begin{array}{c}\text { Altura MS } \\
(\mathbf{m m})\end{array}$ & $\begin{array}{c}\text { Área MS } \\
\mathbf{m m}^{\mathbf{2}}\end{array}$ & $\begin{array}{c}\text { Área ZTA } \\
\mathbf{m m}^{\mathbf{2}}\end{array}$ \\
1,3 & $\mathrm{~S} 1$ & 15,611 & 7,442 & 45,56 & 60,51 \\
1,8 & $\mathrm{~S} 3$ & 17,812 & 10,038 & 75,61 & 340,78 \\
\hline
\end{tabular}

Como pode ser observado o aporte mais baixo, como era esperado, forneceu um cordão de solda com uma largura e penetração ligeiramente menor que o aporte mais alto, consequentemente a área ocupada pelo metal de solda também foi menor para o aporte térmico mais baixo. Quando se realiza uma análise dos resultados obtidos para a área da ZTA como esperado a ZTA do aporte menor ocupa uma área inferior que a ZTA do aporte maior, porém vale ressaltar a diferença desses valores, ou seja, o aporte maior produziu uma ZTA muito maior que o aporte térmico menor.

\subsection{Caracterização microestrutural}

Por meio de análise microscópica, foi possível confirmar que o material no estado como recebido apresenta duas regiões distintas. A região localizada no centro do vergalhão é constituída de ferrita e perlita fina, que possui uma dureza reduzida e uma ductilidade elevada. Já a região externa do vergalhão, é constituída de uma camada de martensita revenida, resultante do processo de produção denominado Thermex sofrido pelo material. Foi realizada a quantificação de fases da região central da amostra como recebida com o auxilio do software Image-Pro o resultado obtido indicou aproximadamente $57 \%$ de perlita e $43 \%$ de ferrita. 0 tamanho de grão obtido com o auxilio do perfilômetro pelo método de Heyn foi de 0,014mm que equivale 9,02ASTM.

A Figura 4 apresenta imagens da zona termicamente afetada (ZTA), para as juntas soldadas com os dois aportes térmicos, onde podem ser observadas muitas mudanças microestruturais na região.
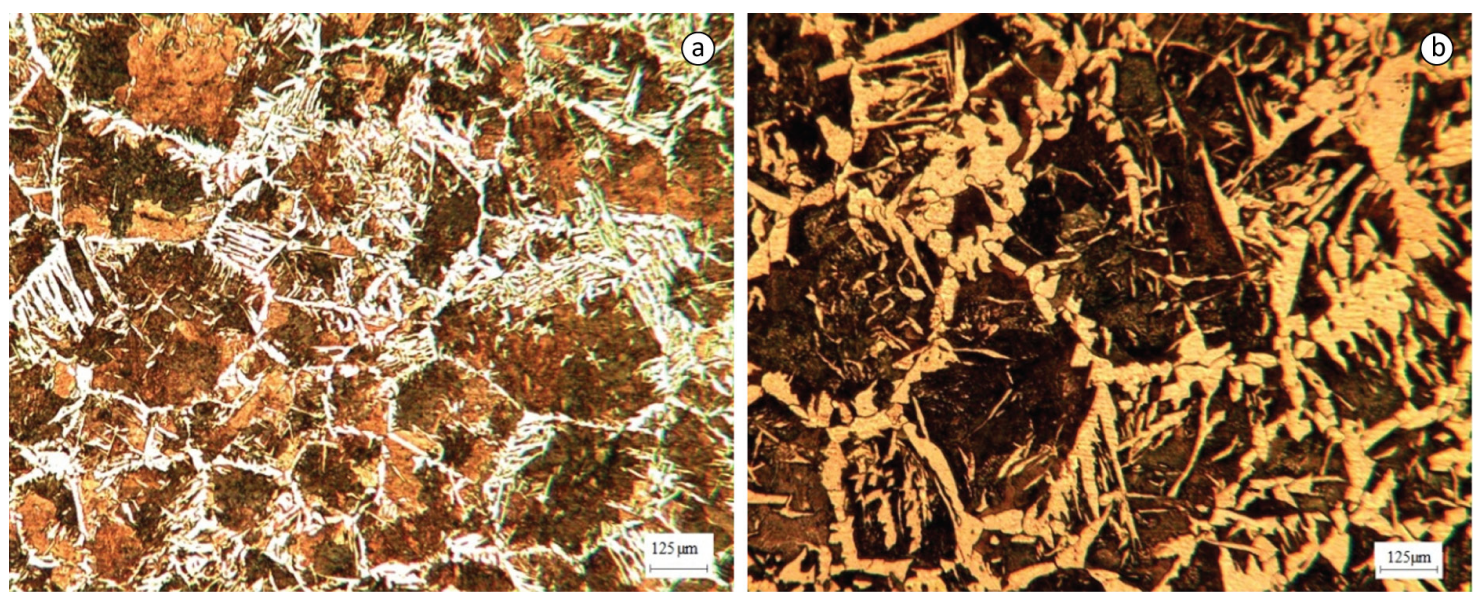

Figura 4. Comparação microestrutural da região da ZTA para dois aportes distintos. Ataque Nital 3\%. Aumento de 200x. (a) ZTA aporte 1,3KJ/mm, com 69\% de perlita e 31\% de ferrita, tamanho de grão 0,027mm (7,13ASTM), (b) ZTA aporte $1,8 \mathrm{KJ} / \mathrm{mm}$, com $54 \%$ de perlita e $46 \%$ de ferrita, tamanho de grão 0,047mm (5,53ASTM). 
Estudo Numérico e Experimental da Evolução Microestrutural e das Propriedades de Juntas Soldadas de Vergalhões pelo Processo GMAW

Por meio da análise microscópica da zona termicamente afetada foi possível observar com a variação do aporte térmico um substancial crescimento dos grãos perlíticos e dos grãos agulhados ao redor dos mesmos, isso ocorreu devido ao aumento do aporte térmico que forneceu mais calor para a junta soldada ocasionando um maior crescimento de grão na ZTA. Através do ensaio de microdureza foi concluído que estes grãos agulhados se tratam de lamelas de ferrita primária de contorno de grão. Esta conclusão foi fundamentada na comparação dos resultados obtidos no ensaio de microdureza com os resultados na literatura. Como os valores obtidos no ensaio foram abaixo $200 \mathrm{HV}$, e como o percentual de carbono na composição química deste aço varia de 0,23\% a 0,28\%, conclui-se que a fase apresentada nos contornos de grão perlíticos na Figura 4 são grãos de ferrita primária que por característica própria possuem esse formato lamelar ou agulhado, e se localizam nos contornos de grão. Também pôde ser observada a presença de ferrita intragranular e ferrita de widmanstätten, a ocorrência dos três tipos de ferrita citados (ferrita de contorno de grão, intragranular e de widmanstätten) aumenta com o aumento do aporte térmico.

Ajustados os parâmetros geométricos do modelo, foi simulada a evolução da distribuição de temperaturas sobre o vergalhão, com forma de cordão de solda e campos de temperatura para os instantes 22s e 44s, apresentada na Figura 5. Nas Figuras 5(a) e (b) observam-se os efeitos na distribuição de temperaturas devido ao movimento da fonte até o final do procedimento de soldagem. Conforme pode ser constatado, durante a soldagem regiões distintas do vergalhão estão sujeitas a aquecimento enquanto outras se encontram em fase de resfriamento. Estes fenômenos são dinâmicos e evidenciam a utilidade de modelos dinâmicos de previsão de temperaturas locais, conforme proposta do presente trabalho. Na Figura 5b, o procedimento de soldagem foi completado e o vergalhão encontra-se em fase intermediária de resfriamento. Vale ressaltar, que embora apenas dois instantâneos de distribuições de temperaturas tenham sido mostrados, o modelo permite a previsão de todo o estado transiente desde o aquecimento até o resfriamento completo, onde o vergalhão volta à temperatura ambiente. Os resultados de distribuição de temperatura sobre os vergalhões permitem ainda prever as dimensões do cordão de solda por meio do traço de uma isoterma na temperatura de fusão do material sobre uma figura tomada transversalmente ao cordão. Esta isoterma delimita a região do cordão de solda.

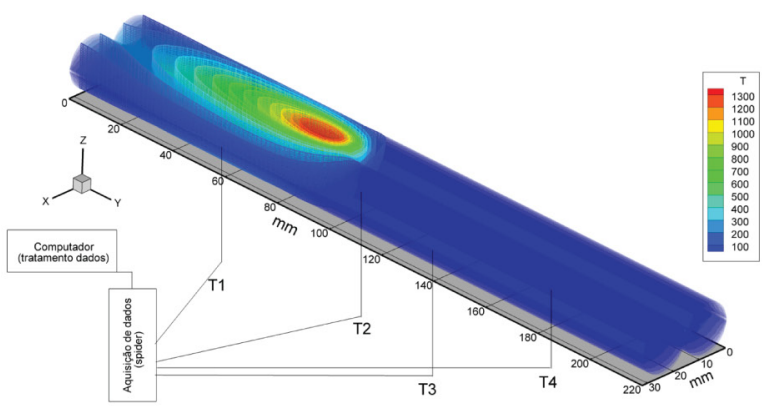

(a) 22 segundos

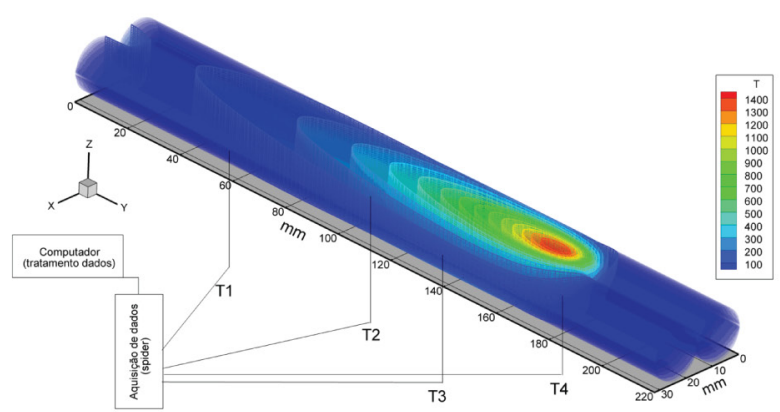

(b) 44 segundos

Figura 5. Evolução dos campos de temperaturas durante o processo de soldagem do vergalhão CA-50 com aporte de $1,3 \mathrm{KJ} / \mathrm{mm}$ calculada pelo modelo numérico.

Os gráficos abaixo (Figura 6) indicam o ciclo térmico experimentado pela região onde foi fixado cada termopar $(\mathrm{T} 1, \mathrm{~T} 2, \mathrm{~T} 3, \mathrm{~T} 4)$ para os dois aportes estudados, indicando a velocidade do aquecimento, tempo que o mesmo levou para chegar a cada ponto (termopar), a temperatura máxima medida pelo termopar, e o resfriamento daquela região do CP. O temopar 1 foi fixado a $60 \mathrm{~mm}$ do início do cordão de solda, o temopar 2 foi fixado a $100 \mathrm{~mm}$ do início do cordão de solda, o temopar 3 foi fixado a $140 \mathrm{~mm}$ do início do cordão de solda, e o temopar 4 foi fixado a $180 \mathrm{~mm}$ do início do cordão de solda.

A Figura 7 apresenta a curva CCT (curva de resfriamento contínuo) do aço utilizado no vergalhão CA-50, através da mesma aliada a curva de resfriamento sofrida pelo material durante o ciclo térmico pode-se definir na teoria as fases que se espera encontrar e confrontar com os resultados encontrados experimentalmente. 

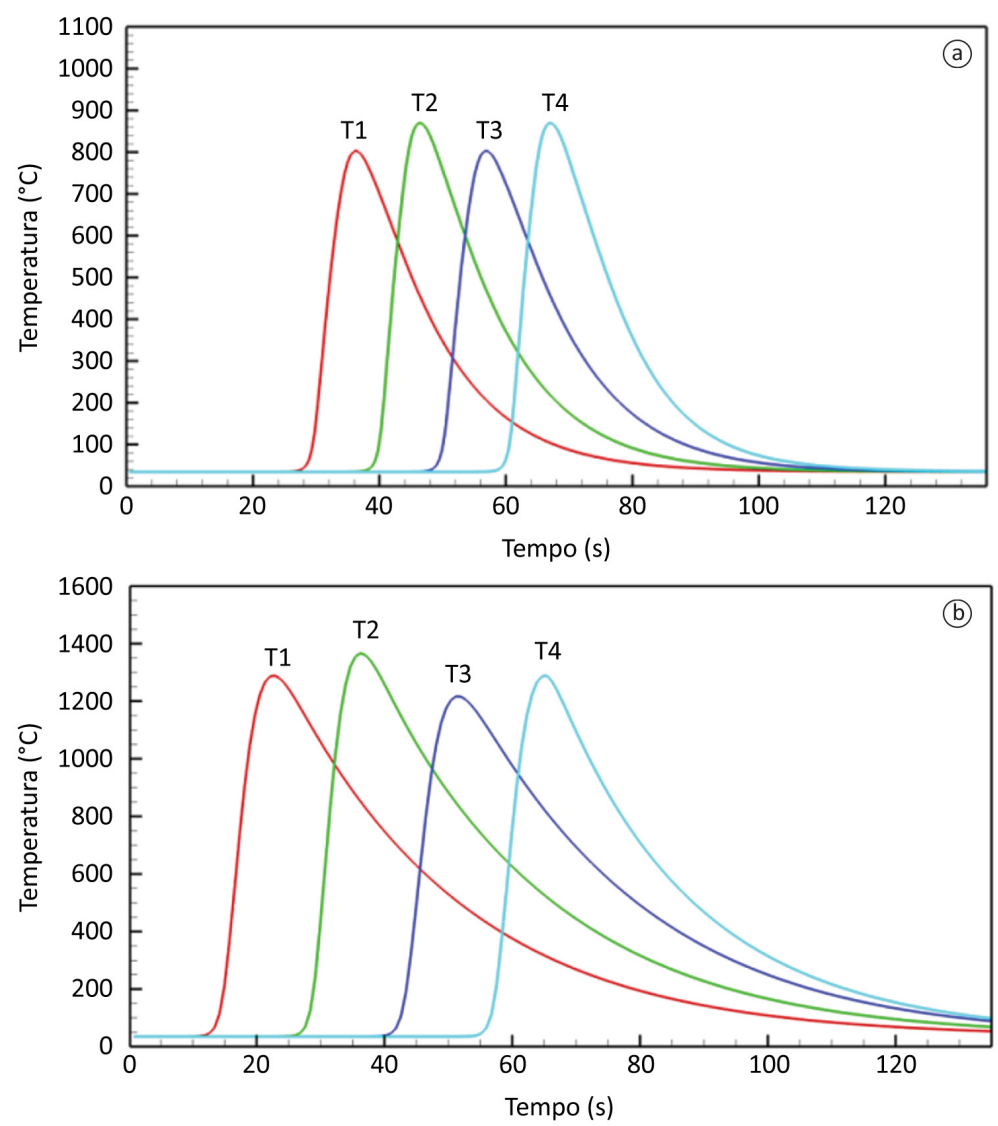

Figura 6. (a) Ciclo térmico sofrido pelo CP nos pontos T1, T2, T3 e T4 experimental. (b) Ciclo térmico sofrido pelo $\mathrm{CP}$ nos pontos T1, T2, T3 e T4 calculado pelo modelo numérico.

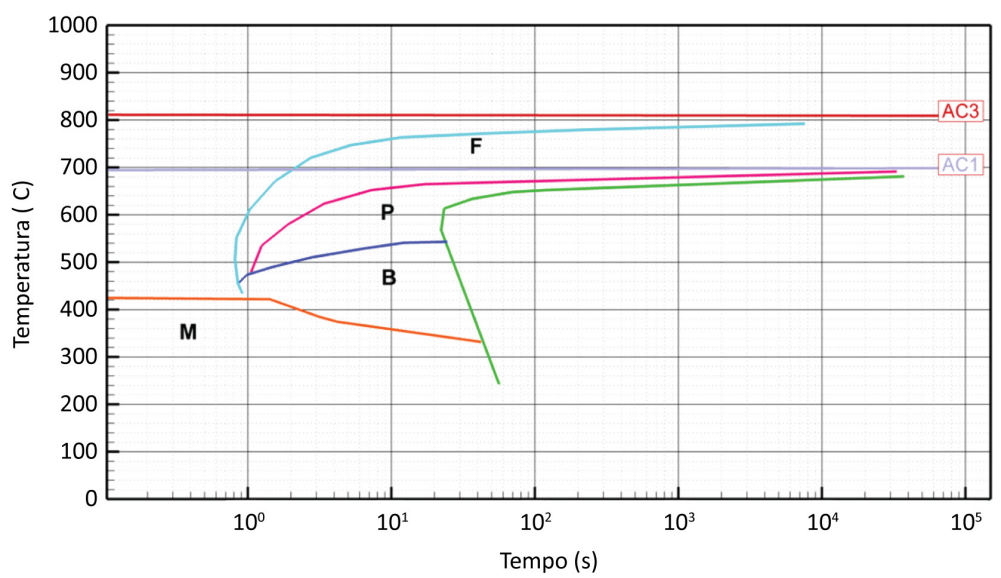

Figura 7. Curva CCT do aço utilizado no vergalhão CA-50.

As Figuras 8 e 9 ilustram de forma comparativa a quantidade de ferrita e perlita formada no corpo de prova após o procedimento de soldagem para os dois aportes térmicos estudados.

Como se pode observar nas figuras comparativas 8 (a) e (b) pode ser concluído que o modelo indica uma significante redução na fração de ferrita quando o aporte térmico é aumentado. Nas figuras comparativas 9 (a) e (b) pode ser concluído que o modelo indica que com o aumento do aporte térmico ocorre um significativo aumento da fração perlítica, a Tabela 4 demonstra isto de forma explícita. Assim como nas figuras comparativas 
Estudo Numérico e Experimental da Evolução Microestrutural e das Propriedades de Juntas Soldadas de Vergalhões pelo Processo GMAW

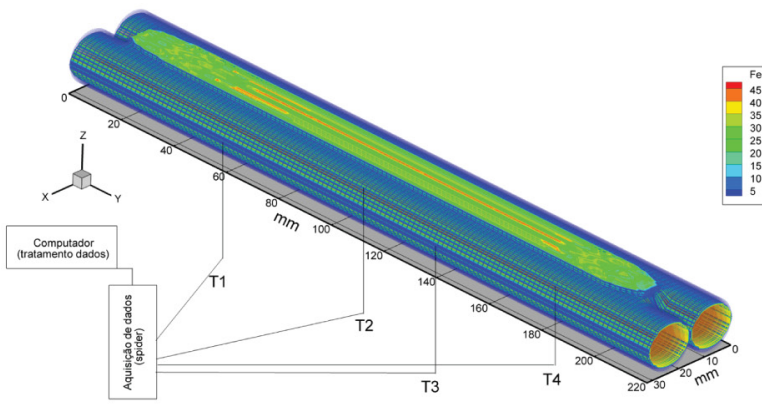

(a) aporte de $1,3 \mathrm{KJ} / \mathrm{mm}$

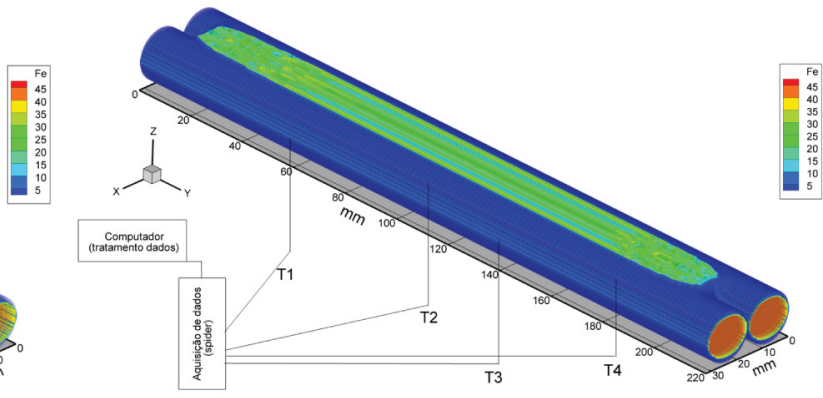

(b) aporte de $1,8 \mathrm{KJ} / \mathrm{mm}$

Figura 8. Quantidade de Ferrita calculada pelo modelo numérico.

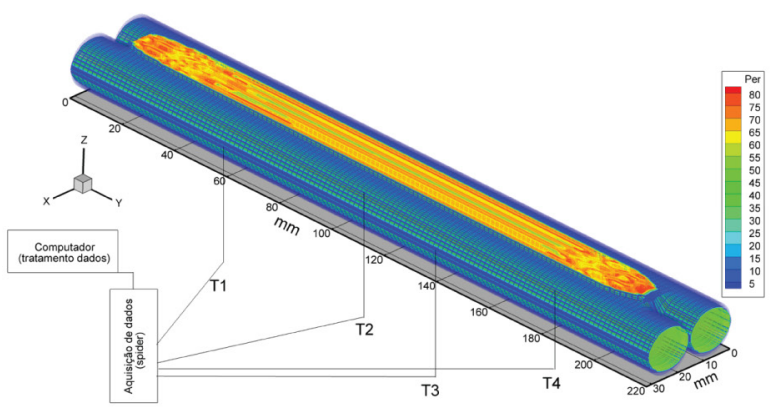

(a) aporte de $1,3 \mathrm{KJ} / \mathrm{mm}$

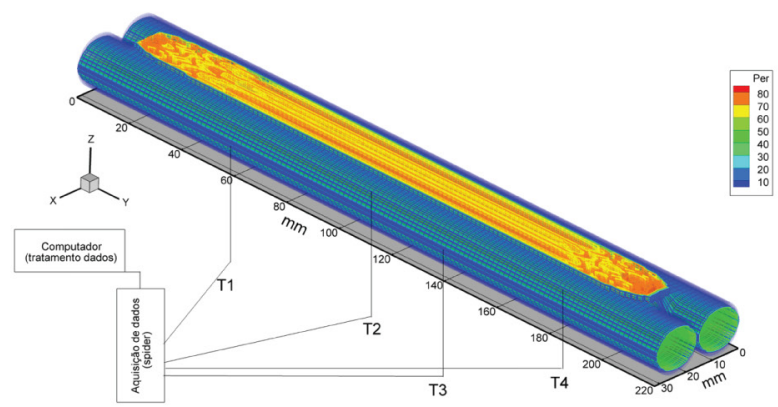

(b) $1,8 \mathrm{KJ} / \mathrm{mm}$

Figura 9. Quantidade de Perlita calculada pelo modelo numérico.

Tabela 4. Quantificação de fases do material no estado como recebido, e da região da ZTA para as soldagens com os dois aportes diferentes.

\begin{tabular}{ccc}
\hline Amostra & \%Perlita & \%Ferrita \\
CR & 62,69 & 37,31 \\
S1 & 29 & 71 \\
S3 & 41,5 & 58,5 \\
\hline
\end{tabular}

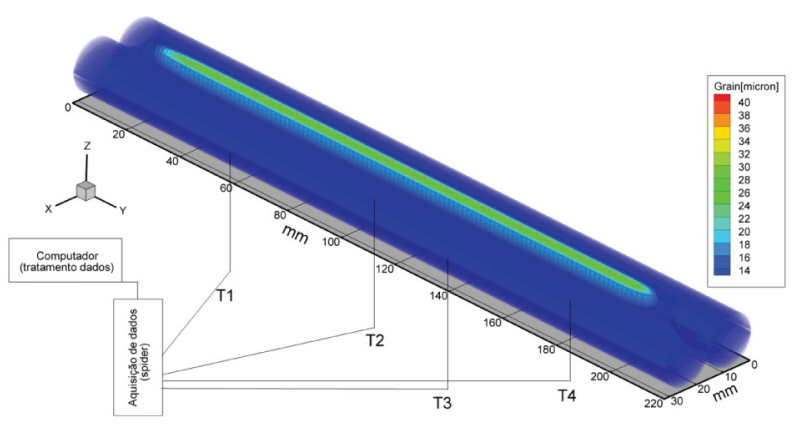

(a) aporte de $1,3 \mathrm{KJ} / \mathrm{mm}$

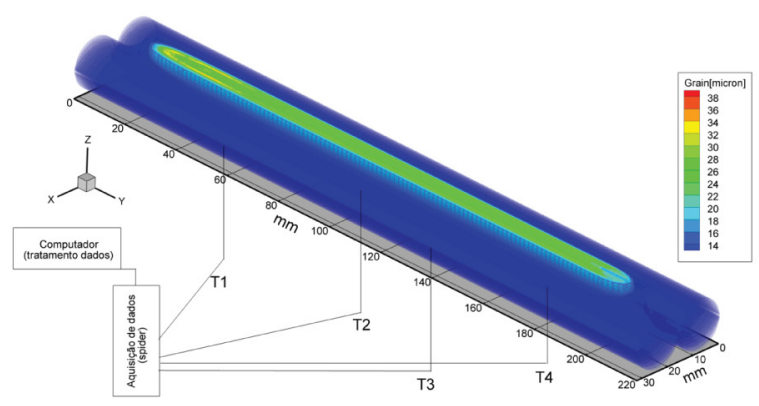

(b) aporte de $1,8 \mathrm{KJ} / \mathrm{mm}$

Figura 10. Tamanho de grão calculado pelo modelo numérico. 
(Figura 10 (a) e (b)) pode ser concluído que o modelo indica um considerável aumento no tamanho de grão na região da ZTA. Isso pode ser concluído observando as cores indicadas no cordão de solda, e comparando-as com as cores indicadas nas legendas associadas a um percentual. Para melhor compreensão observe a Tabela 4.

Conforme citado anteriormente foi realizada a soldagem segundo a norma NBR 6118 [6]. Estes corpos de prova foram submetidos ao ensaio de tração segundo a mesma norma. Para o menor aporte a junta soldada rompeu fora da região soldada, fato essencial para se garantir que a solda realizada foi de qualidade. Já para o maior aporte a junta soldada se rompeu no início do cordão de solda, fato que segundo a norma NBR 8548 reprova a junta soldada [15]. Isso pode ser observado na Figura 11.
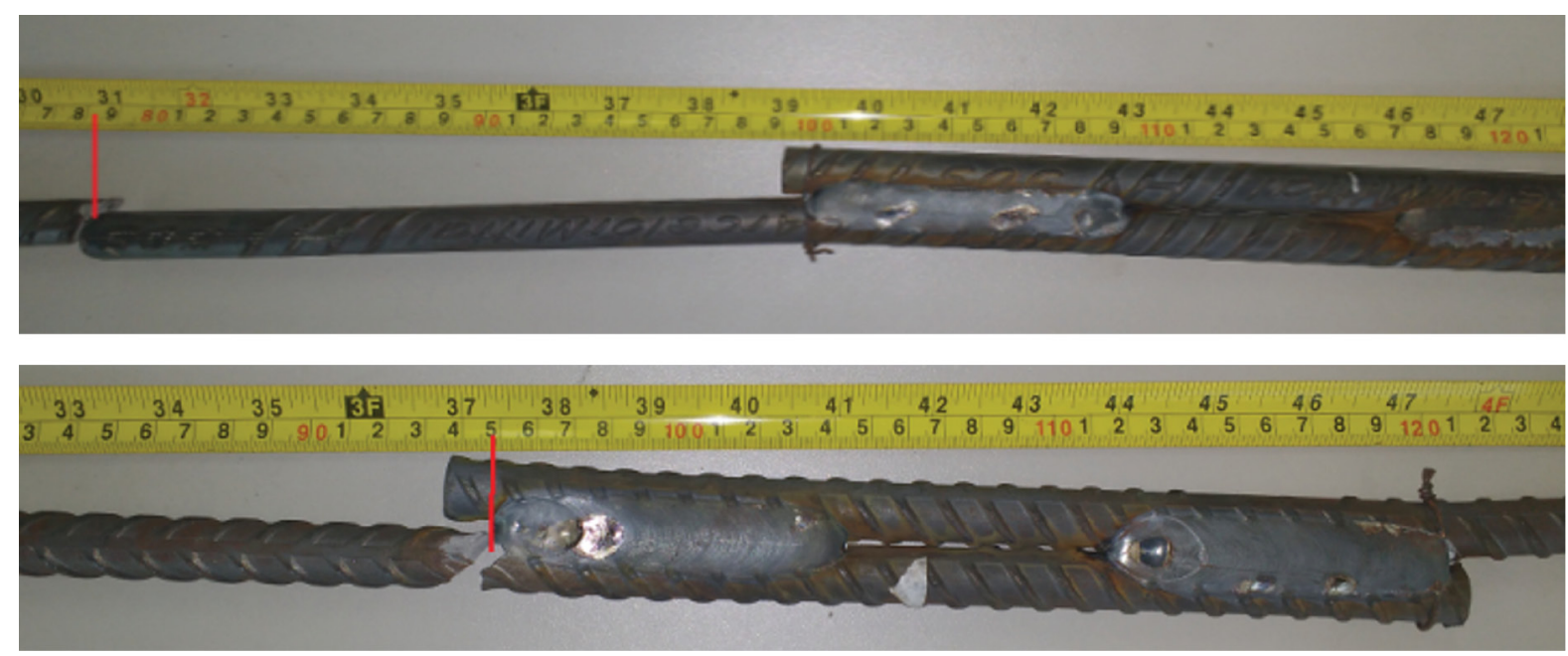

Figura 11. Junta soldada com aporte de 1,3KJ/mm e 1,8KJ/mm respectivamente, após ensaio de tração.

\section{Conclusões}

Através de análises das microestruturais da ZTA, conclui-se que o comportamento da região se manteve dentro do esperado, pois com o aumento do aporte térmico foi observado um aumento na área da ZTA, assim como um aumento no tamanho de grão médio, que passou de $0,027 \mathrm{~mm}(7,13 \mathrm{ASTM})$ com aporte de 1,3KJ/mm para $0,047 \mathrm{~mm}(5,53 \mathrm{ASTM})$ com aporte de $1,8 \mathrm{KJ} / \mathrm{mm}$. Se forem comparados os valores do tamanho de grão na ZTA com o valor do tamanho de grão medido no material como recebido, que é de $0,014 \mathrm{~mm}(9,02$ ASTM), oque também está dentro do comportamento esperado, pois os grãos da ZTA tendem a serem maiores que do metal base. A ZTA também apresentou uma estrutura perlítica com ferrita de contorno de grão, ferrita intragranular e ferrita de widmanstätten.

O metal de solda também apresentou um comportamento dentro do esperado, pois com o aumento do aporte térmico ocorreu um aumento nas dimensões do cordão de solda, como largura e profundidade.

Utilizando os resultados dos ensaios de tração aliados aos resultados de medida de tamanho de grão e análise microestrutural, conclui-se que as soldas realizadas com o aporte térmico de $1,3 \mathrm{KJ} / \mathrm{mm}$ passaram na análise de qualidade, pois seus corpos de prova romperam fora da região soldada, logo conclui-se que o processo introduziu uma fragilidade apenas no aporte de $1,8 \mathrm{KJ} / \mathrm{mm}$, o que significa que o aumento do aporte térmico tendeu a favorecer o crescimento de grãos na ZTA, com isso reduzindo a resistência do metal nessa região e favorecendo o rompimento da junta soldada nesta região, oque implicou na reprovação da solda utilizando o aporte de 1,8KJ/mm.

O modelo numérico utilizado mostrou-se eficiente para previsão de temperatura diante dos ciclos térmicos calculados e medidos. Já o modelo de duplo elipsoide utilizado para fonte de calor não apresentou grande variação em relação à taxa prevista, portanto conclui-se que pequenos erros na determinação de parâmetros não resultariam em imprecisões significativas na previsão de transformações de fases difusionais. 
Estudo Numérico e Experimental da Evolução Microestrutural e das Propriedades de Juntas Soldadas de Vergalhões pelo Processo GMAW

\section{Referências}

[1] Bastos PSS. Fundamentos do concreto armado. Bauru: UNESP; 2006.

[2] Costa ALV, Silva PR. MEl: aços e ligas especiais. 2. ed. São Paulo: Edgard Blücher; 2010.

[3] Daroit RS. Análise de estruturas viscoelásticas [dissertação de mestrado]. Porto Alegre: Universidade Federal do Rio Grande do Sul; 2012.

[4] Chiaverini V. Tecnologia mecânica. 2. ed. São Paulo: McGrawHill; 1986. p. 78-95. (Materiais de Construção Mecânica, 3).

[5] CofiñoSP. Análise das tensões residuais em uma junta soldada em Condição Overmatch [dissertação de mestrado]. Santo André: Universidade Federal do ABC; 2010.

[6] Associação Brasileira de Normas Técnicas. ABNT NBR 6118: Projeto e execução de obras de concreto armado. Rio de Janeiro: ABNT; 2014.

[7] Alonso SC. Caracterização de união por solda de tôpo em barras Ca-50 com eletrodos revestidos [dissertação de mestrado]. Florianópolis: Universidade Federal de Santa Catarina; 2006.

[8] Bortoleto SP. Modelamento numérico computacional das transformações de fases nos tratamentos térmicos de aços [dissertação de mestrado]. São Paulo: Escola Politécnica, Universidade de São Paulo; 2010.

[9] Almeida MGR. Modelagem do efeito da taxa de aquecimento na cinética de formação da austenita em aço baixo carbono

[dissertação de mestrado]. Ouro Preto: Universidade Federal de Ouro Preto; 2010.

[10] Babu K, Prasanna Kumar TS. Comparison of austenite decomposition models during finite element simulation of water quenching and air cooling of AISI 4140 steel. Metallurgical and Materials Transactions B. 2014;45(4):1530-1544.

[11] Seok-J L, Erik JP, Chester JVT. Kinetics modeling of austenite decomposition for an end-quenched 1045 steel. Materials Science and Engineering A. 2010;527(13-14):3186-3194. http:// dx.doi.org/10.1016/j.msea.2010.01.081.

[12] Ontman AYM, Shiflet GJ. Thermodynamic mapping of austenite decomposition's approach toward equilibrium in $\mathrm{Fe}-\mathrm{C}-\mathrm{Mn}$ at 700 C. Acta Materialia. 2015;89:98-108. http://dx.doi. org/10.1016/j.actamat.2015.01.001.

[13] Xavier CR, Delgado HG Jr, Castro JA. Numerical evaluation of the weldability of the low alloy ferritic steels T/P23 and T/P24. Materials Research. 2011;14(1):73-90. http://dx.doi.org/10.1590/ S1516-14392011005000019.

[14] Li MV, Niebuhr DV, Meekisho LL, Atteridge DG. A computational model for the prediction of steel hardenability. Metallurgical and Materials Transactions B. 1998;29B:661-672. http://dx.doi. org/10.1007/s11663-998-0101-3.

[15] Associação Brasileira de Normas Técnicas. ABNT NBR 8548: Barras de aço destinadas a armaduras para concreto armado com emenda mecânica ou por solda - Determinação da resistência à tração - Método de ensaio. Rio de Janeiro: ABNT; 1984. 